\title{
The Relationship between Expression of p70s6k with Radiotherapy Response in Cervical Cancer
}

\author{
I. Kurnia ${ }^{1^{\star}}$, B. Siregar ${ }^{2}$, Z. Alatas ${ }^{1}$, I. Ramli ${ }^{2}$, T. Kurjana ${ }^{3}$, A. Andriono ${ }^{2}$, M.D.L. Tobing ${ }^{3}$, \\ B.S. Hernowo ${ }^{3}$, T. Kisnanto ${ }^{1}$, Y. Lusiyanti ${ }^{1}$, D. Tetriana ${ }^{1}$ and S. Soetopo ${ }^{3}$ \\ ${ }^{1}$ Center for Radiation Safety Technology and Metrology, National Nuclear Energy Agency \\ Jl. Lebak Bulus Raya No.49, Jakarta 12440, Indonesia \\ ${ }^{2}$ Cipto Mangunkusumo Hospital, Jalan Diponegoro No.71, Jakarta 10430, Indonesia \\ ${ }^{3}$ Hasan Sadikin Hospital, Jalan Pasteur No.38, Bandung 40161, Indonesia
}

\section{ARTICLE INFO}

\section{Article history:}

Received 22 October 2014

Received in revised form 3 July 2015

Accepted 31 July 2015

\section{Keywords:}

Cervical cancer

Radiotherapy

p70s6k

\begin{abstract}
A B S T R A C T
There are many important prognostic factors in advanced stage cervical cancer primary treated with radiotherapy. Besides clinical factors, many biomarkers have been studied in relation with radiotherapy response. The p70s6k is a biomarker which plays a significant role in cell proliferation. Increased levels of p70s6k are also associated with drug resistance in cancer. In the present study, the relationship between the expression level of p70s6k before treatment and the radiotherapy response in cervical cancer was determined. Immunohistochemical staining of p70s6k, MIB-1, and p53 was conducted in microscopic slide from 21 cancer tissue biopsies before treatment with radiotherapy. After the treatment had completed early radiotherapy response was observed by pelvic control method. The results showed that p70s6k is partly highly expressed $(61.9 \%, 13 / 21)$ and partly low expressed $(38.1 \%, 8 / 21)$ in the cancer cells. They also show that there is no statistically significant differences on AgNOR mean, MIB-1, and p53 indices in the different degrees of $\mathrm{p} 70 \mathrm{~s} 6 \mathrm{k}$ expression ( $\mathrm{p} \geq 0.05$ ). Higher expression levels of $\mathrm{p} 70 \mathrm{~s} 6 \mathrm{k}$ is more strongly associated with good radiotherapy response compared to lower ones $(\mathrm{p}=0.05)$. In conclusion, the level of $\mathrm{p} 70 \mathrm{~s} 6 \mathrm{k}$ expression before treatment has an association with radiotherapy response.
\end{abstract}

\section{INTRODUCTION}

Cervical cancer is the most frequently found malignancy disease in Indonesia. Usually, patients come to the hospital when already at a locallyadvanced stage. One of the treatment choices in locally-advanced form of this cancer is radiotherapy. This treatment could sometimes be combined with chemotherapy, resulting in what is known as concurrent chemoradiotherapy [1,2].

There are many important prognostic factors in advanced-stage cervical cancer that are primarily treated with chemoradiotherapy, such as clinical pathologic factors, including stage and tumor histology [3]. Besides the clinical pathologic factors, many biomarkers have been studied in

*Corresponding author

E-mail address: kurnia@batan.go.id

DOI: http://dx.doi.org/10.17146/aij.2016.478 relation to the patient's survival and/or response to chemoradiotherapy. Biomarkers are biological molecules in body fluids or tissues that are quantitatively measured and evaluated as indicators of normal biological processes, pathogenesis, or pharmacologic response to a therapeutic intervention [4]. Clearly response to chemoradiotherapy as a part of therapeutic intervention can also be predicted by measuring some biomarkesr. At present, the focus of improving survival rates is mainly on targeted therapies in combination with standard chemoradiotherapy [5].

The $\mathrm{p} 70 \mathrm{~s} 6 \mathrm{k}$ is a serine/threonine protein kinase responsible for the phosphorylation and activation of 40S ribosomal subunit protein S6 [6]. It acts downstream of the mammalian target of rapamycin (mTOR) in Akt pathway. The activation target of p70s6k and its downstream are ribosomal 
protein S6 mediates nutrient and mitogen-stimulated translation, which is essential for cell growth and proliferation [7]. In some in vitro studies, it was found that activity of $\mathrm{p} 70 \mathrm{~s} 6 \mathrm{k}$ is related to the prevention of apoptosis as one of the death processes in cancer cell treatment with radiotherapy that can be induced with intrinsic or extrinsic DNA damage $[8,9]$.

Nucleolar organizer regions (NORs) are chromosomal segments that carry ribosomal genes. Silver-stained NORs are called AgNORs and when examined using light microscopy they appear as well-defined black dots which are exclusively located within the nucleoli [10]. The MIB-1 is a monoclonal antibody to detect Ki-67 antigen. This antigen can be detected in the nuclei of cells during the gap1 (G1), synthesis (S), gap2 (G2), and mitosis (M) phases of the cell cycle. Thus, it can only be detected in the nuclei of proliferating cells in all active phases of the cell-division cycle, but is absent in non-proliferating cells [11]. The p53 gene, located on chromosome 17, encodes a $53-\mathrm{kDa}$ protein. The wild-type $\mathrm{p} 53$ protein is a transcription factor that, when activated, acts to arrest cells temporarily in the G1/G2 phase of the cell cycle, thus allowing time for the repair of the damaged DNA, or to cause cells to proceed to apoptosis if the DNA damage is irreparable [12].

Our previous publications reported a correlation between apoptosis caspase- 3 and better radiotherapy response. However, the high level of Akt indicated poor radiotherapy response, and there were no association between some proliferation markers like AgNOR, MIB-1, and p53 with radiotherapy response [13,14]. The aim of the present study is to investigate the relationship between $\mathrm{p} 70 \mathrm{~s} 6 \mathrm{k}$ as biomarker and radiotherapy response in cervical cancer.

\section{EXPERIMENTAL METHODS}

\section{Patients}

Twenty one consecutive patients who have undergone complete treatments, from a whole series of 60 cases who suffered from non-metastatic localized cervical carcinoma in local advance stage (IIB-IIIB), were prospectively conducted from July 2010 to March 2011. All the 60 patients satisfied the inclusion criteria but did not complete biopsy and clinical data. All the 21 chosen patients were diagnosed and treated by definitive concurrent chemoradiotherapy in the Cipto Mangunkusumo and Hasan Sadikin Hospitals. The radiation therapy treatment conducted included external and internal radiation, namely external beam radiotherapy
(EBRT) using Co-60 with a total dose of 50 Gy in 25 fractions and internal radiation with ${ }^{192}$ Ir high dose-rate intracavitary brachytherapy (HDR-ICBT) using a microSelectron (Nucletron International, Amsterdam, Netherlands) followed by EBRT in two fractions (850 cGy/fraction). Cisplatin as a chemoradiotherapic agent was administered at a dose of $40 \mathrm{mg} / \mathrm{m}^{2}$ on days $1,8,15,22$, and 29 ; it was given concurrently with the EBRT in 2 hours or less before the treatment for the corresponding day. The process of diagnosis and treatment followed the Standard Operation Procedure (SOP) as shown in our previous publication [13].

Before the studies were carried out, the research proposal was approved by the Health Research Ethics Committee, Faculty of Medicine, University of Indonesia, and the patients received written informed consent document.

\section{Radiotherapy Response}

Tumor response to radiation therapy was evaluated by radiotherapists by pelvic control [15]:

1. NRT (no gross residual tumor) response as good response is a complete or nearly complete regression of pelvic tumor, non-specific fibrosis, or granulation over the cervix.

2. GT (gross residual tumor) response as a bad response is gross tumor or palpable nodularity on cervix, and/or palpable in duration on the parametrium.

\section{AgNOR and Immunohistochemistry}

AgNOR staining (silver staining) and immunohistochemistry of MIB-1, p53, and p70s6k were performed on microscopic slides obtained from cancer tissue biopsy before treatment with radiotherapy. A simple silver staining technique was performed in accordance with the technique described by Ploton et al. [16]. Tissue sections, $4 \mu \mathrm{m}$ thick, were cut from formalin fixed, paraffinwax embedded blocks. The sections were dewaxed in xylene and then hydrated through decreasing grades of ethanol followed by washing in deionized water for 8-10 minutes. The staining solution was prepared by dissolution of powdered gelatin with concentration of $2 \% \mathrm{w} / \mathrm{v}$ in deionized water over water bath at $60-70^{\circ} \mathrm{C}$. Pure formic acid was then added to a final concentration of $1 \%$. This solution was mixed $1: 2(\mathrm{v} / \mathrm{v})$ with $50 \%$ aqueous silver nitrate solution (freshly made each time), filtered through a $0.22 \mathrm{~mm}$ Millipore filter, and dropped onto the slide-mounted section. The sections were incubated in the dark for 40-45 minutes at room temperature. 
After rinsing three times with deionized water, the slides were immersed for 10 minutes in 5\% sodium thiosulphate solution, dehydrated in ascending ethanol concentrations, cleared with xylene, and mounted.

In immunohistochemistry, after dewaxing process as in AgNOR staining, tissue sections were washed with phosphate-buffered saline (PBS) three times (5 minutes each). The sections were incubated in Dako Target Retrieval Buffer (pH 6: DakoCytomation, Denmark) in a microwave oven at $94^{\circ} \mathrm{C}$ for 20 minutes, cooled to room temperature for 20 minutes, and washed in PBS ( 3 times for 5 minutes each). Then, the sections were incubated with Dako Peroxidase Block (DakoCytomation) for 10 minutes, followed by PBS for 10 minutes, and incubation with anti p70s6k, MIB-1 and anti-p53 antibodies, overnight at $4^{\circ} \mathrm{C}$. After incubation with antibodies, the sections were washed with PBS for 15 minutes, and incubated with secondary antibody (Labeled Polymer HRP from DakoCytomation) for 60 minutes at room temperature. Then, the sections were washed with PBS for 10 minutes, developed with 3,3'-diaminobenzidine tetrahydrochloride for 30 seconds, slightly counterstained with hematoxylin, dehydrated, and mounted; this technique was done with some modifications from the original method [17]. p70s6k expression is observed in the nucleus and cell cytoplasm. The degree of its expression was estimated blindly to the clinical patient characteristics and outcome, using microscope magnification $(10 \times 40)$ semiquantitatively. The scores were from negative $(-)$ to slightly positive $(+)$, moderately positive $(++)$ and strongly positive $(+++)$. [18]. The scores from negative to slightly positive were grouped as "low expression" (1) while moderate to strong positive was grouped as "high expression."

\section{Statistical Analysis}

Analysis of variance (ANOVA) test was used in the comparison between expression of p70s6k and AgNOR mean, MIB-1 index and p53 index before treatment. Fisher Exact Test was used in the comparison between expressions of p70s6k with radiotherapy response. All tests used $\mathrm{p} \leq 0.05$ as statistical significance criterion. Minitab 17 was used for data analysis.

\section{RESULTS AND DISCUSSION}

The expression of p70s6k was identified as brown color in the nuclei and cytoplasm of cancer cells as shown in Figs. 1 (a) and 1 (b) (with the blue arrow). Its expression was observed in all of the 21 microscopic slides from cancer tissue slides before radiotherapy. Then, they can be classified into two groups, namely the High Expression of p70s6k group $(61.9 \%, 13 / 21)$ or also classified as 2, and Low Expression of p70s6k group $(38.1 \%, 8 / 21)$, or also classified as 1 ; this is shown in Fig. 2 and Fig. 3 (those two groups will afterwards be also simply referred to as "High Expression" and "Low Expression", respectively). Table 1 shows that between the two groups (High Expression vs. Low Expression) there is no statistically significant difference in AgNOR mean, MIB-1, and p53 index. In contrast to the AgNOR mean that tends to be lower in the High Expression group, both MIB-1 and p53 index appear to be higher in the High Expression group than in the Low Expression group (Fig. 2 a,b,c). After radiotherapy, however, there were statistically significant differences in the proportions of complete and partial radiotherapy responses between the High and Low Expression of $\mathrm{p} 70 \mathrm{~s} 6 \mathrm{k}$ groups at $\mathrm{p}=0.05$, as shown in Fig. 3.

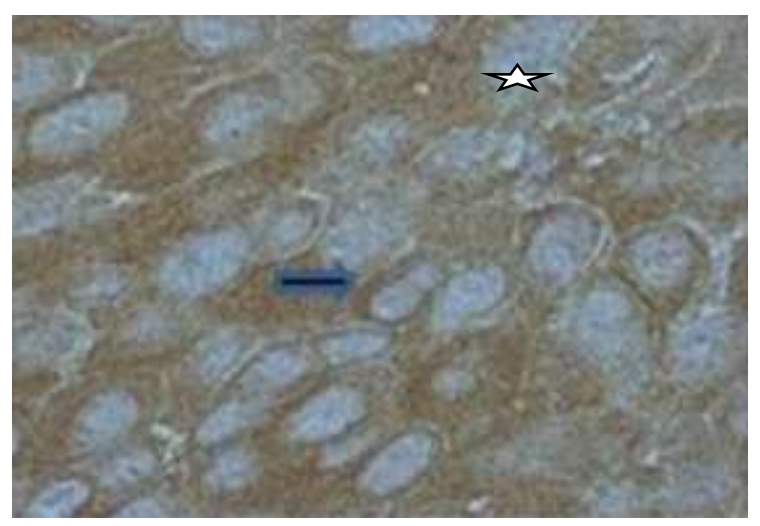

(a)

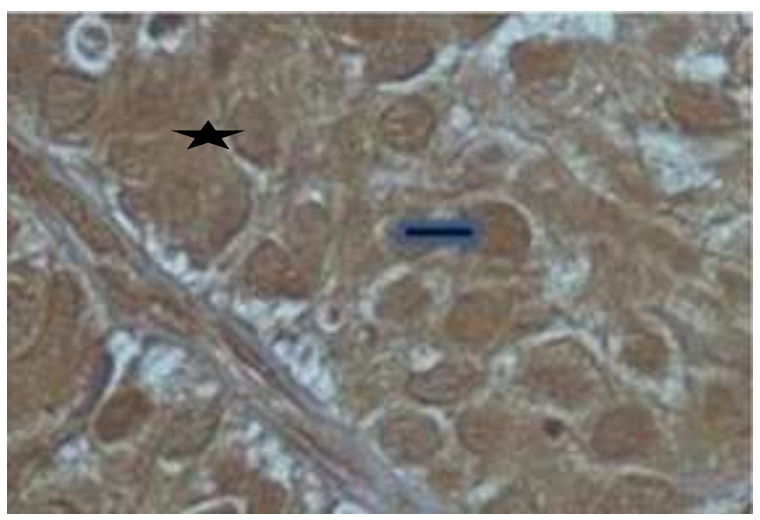

(b)

Fig 1. Expression of p70s6k in cytoplasm (a) and nucleus (b) in cervical cancer before treatment with radiotherapy (original magnification $10 \times 40$ ). The white star indicates low expression and the black star indicates high expression. 


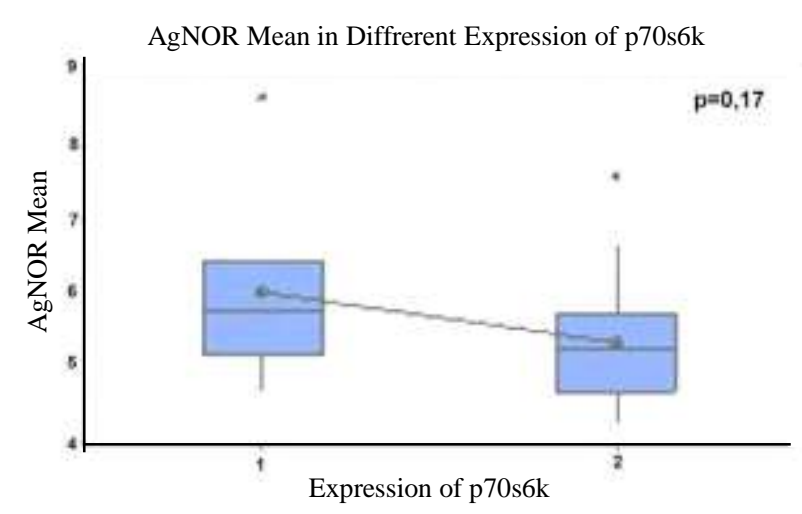

(a)

MIB-1 Index in two Mean Diffrerent Expression of p70s6k

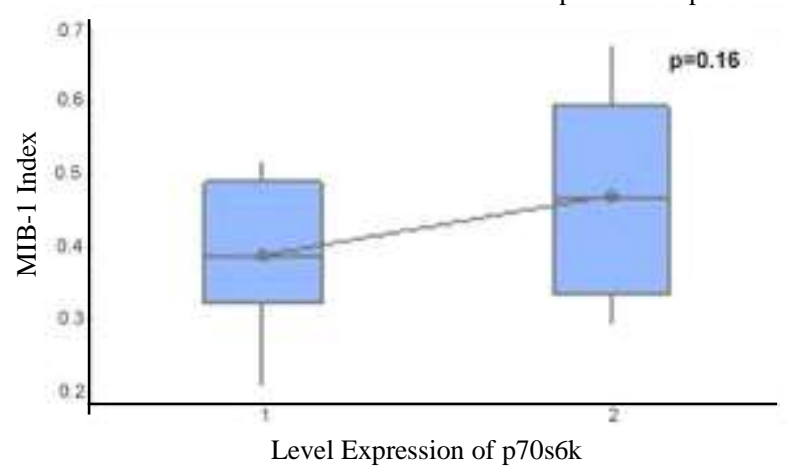

(b)

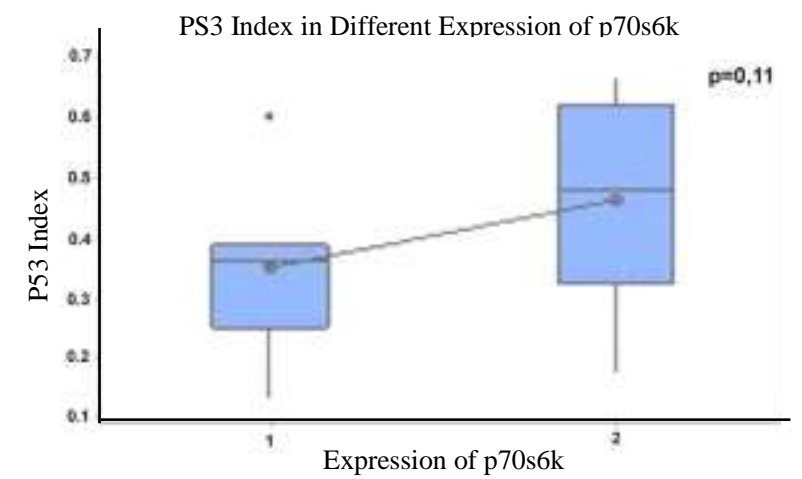

(c)

Fig. 2. AgNOR mean (a), MIB-1 indices (b), and p53 indices (c) in different expressions of p70s6k in cervical cancer before treatment with radiotherapy.

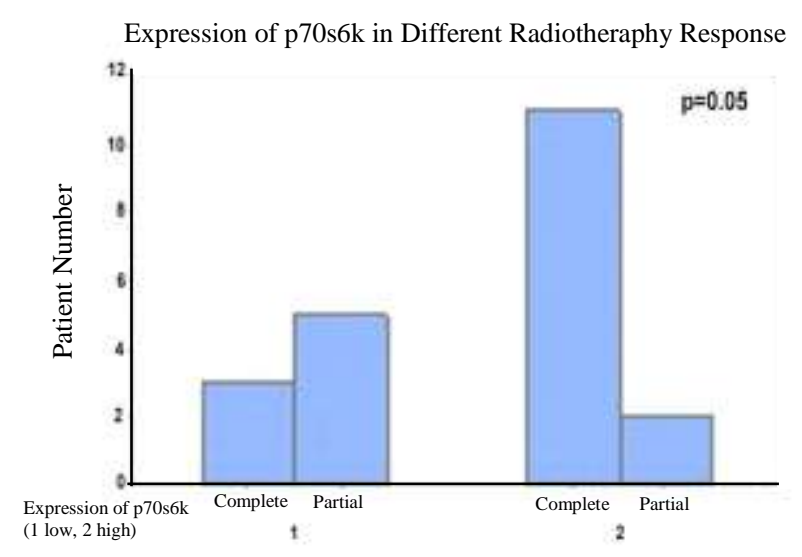

Fig. 3. Expression of p70s6k in different radiotherapy responses.
The low AgNOR mean in the High Expression of p70s6k group is related to the different activity sites of p70s6k and AgNOR in the parts of cell cycle. AgNOR can be identified in G1, $\mathrm{S}$, and G2 in the cell cycle, where p70s6k expression is observed only in G1. AgNOR will increase from $\mathrm{G} 1$ and accumulate in $\mathrm{S}$, then decrease in $\mathrm{G} 2$ as observed in cervical cancer tissues before treatment and after 9-Gy irradiation AgNOR in after 9-Gy irradiation as considered in G2 phase and $S$ phase before irradiation [10]. As a mitogenactivated Ser/Thr protein kinase, p70s6k is required for $\mathrm{G} 1$ cell cycle progression and cell proliferation [9].

The high expression of p70s6k is related to cell proliferation. Among actively-proliferating cells, the number of cells in mitosis (cycling cell) is higher than the number of cells in the G0 phase. High MIB-1 indices that appear in the High Expression group Table 1 are also relevant for studies of breast cancer and in-vitro studies using mammalian cells [19,20]. A high MIB-1 index indicates that the fraction of cancer cells growing is high [17].

Table 1. AgNOR mean, MIB-1 index and p53 index in different expression of $\mathrm{p} 70 \mathrm{~s} 6 \mathrm{k}$

\begin{tabular}{lccc}
\hline \multicolumn{1}{c}{ Biomarker } & $\begin{array}{c}\text { Low Expression } \\
\text { of p70s6k }\end{array}$ & $\begin{array}{c}\text { High Expression } \\
\text { of p70s6k }\end{array}$ & $\mathrm{p}$ value \\
\hline AgNOR Mean & $6.01 \pm 1,23(\mathrm{n}=8)$ & $5,33 \pm 0,94(\mathrm{n}=13)$ & $0.17 \mathrm{~ns}$ \\
MIB-1 Index & $0,39 \pm 0.10(\mathrm{n}=8)$ & $0.47 \pm 0,13(\mathrm{n}=13)$ & $0.16 \mathrm{~ns}$ \\
P53 Index & $0.34 \pm 0.13(\mathrm{n}=8)$ & $0.46 \pm 0.16(\mathrm{n}=13)$ & $0.11 \mathrm{~ns}$ \\
\hline
\end{tabular}

The high p53 index in the High Expression group in Table 1 was due to the presence of most expression of p53 in cervical cancer in mutant rather than in wild type, even though DNA sequencing analysis was not performed. An in-vitro investigation reported that wild type p53 can decrease the p70s6k expression by mTOR pathway [21].

After treatment with radiotherapy, there were statistical differences in proportions of complete and partial radiotherapy response between the High and Low Expression of $\mathrm{p} 70 \mathrm{~s} 6 \mathrm{k}$ groups $(\mathrm{p}=0.05)$. The high expression of $\mathrm{p} 70 \mathrm{~s} 6 \mathrm{k}$ in this current study indicates the presence of highly proliferating cells that also prevent the process of apoptosis as one of the death mechanisms of cancer cell after receiving exposure of ionizing radiation in radiotherapy. The high portion of proliferating cells also indicate the cells would be more radiosensitive rather than radioresistant. A number of studies have focused on the involvement of p70s6k in influencing cellular responses to apoptotic stimuli $[8,9]$. Treatment of Swiss 3T3 and RAT-1 cells with etoposide and 
staurosporine resulted in dephosphorylation and decreased activity of p70s6k in preventing apoptosis. It has also been shown that cisplatin inhibits the phosphorylation of p70s6k in mouse myoblasts [10]. Another in vitro study, using breast cancer cell, found that inactivation of p70s6k also allows the process of cell death to proceed and potentially sensitizes cancer cell to chemotherapeutic agents [22].

Cells in high proliferation were highly radiosensitive and thus giving good radiotherapy response, while cells in lower proliferation proportion will give worse radiotherapy response. Because in this result the observation of radiotherapy response was early response, we think that majority of cancer cell death was caused by irradiation rather than cisplatin in concurrent chemoradiotherapy. Ons study with HeLa cells indicate that overexpression of $\mathrm{p} 70 \mathrm{~s} 6 \mathrm{k}$ protein can induce the process of apoptosis via Bax and Baxindependent pathways [23].

The present results seems to be different from some reports explaining the relation between expression level of $\mathrm{p} 70 \mathrm{~s} 6 \mathrm{k}$ and the resistance of some cancer cells after treatment. High expression of p70s6k before treatment is related with resistance of cancer cells or poor response toward cancer treatment [20].

\section{CONCLUSION}

The expression of p70s6 $\mathrm{k}$ has an important role in cell cancer proliferation in making the cancer more radiosensitive or radioresistant and thus exhibits a potential in predicting the radiotherapy response. It is also as a parameter to be considered in patient selection before treatment.

\section{ACKNOWLEDGMENT}

This research was supported by a Research Grant from the Center for Technology of Radiation Safety and Metrology, National Nuclear Energy, for Fiscal Year 2011. The authors thank Dr. Mukh. Syaifudin, Head of Radiobiology Group, Division of Nuclear Medicine Technique and Radiation Biology, Center for Technology of Radiation Safety and Metrology, National Nuclear EnergyAgency for reviewing and editing this manuscript.

\section{REFERENCES}

1. M.F. Aziz. Gynaecol. Oncol. 20 (2009) 8.
2. S. Mufyala and A.H. Wofson, Cervical Cancer, In: Radiation Oncology. An Evidence Base Approach, J.J. Lu and L.W. Brady (Eds), Springer, Berlin (2008) 357.

3. L. Annika, Prognostic factors for squamous cell cervical cancer, Ph.D. Thesis, Umeå University (2010).

4. J.A. Strimbu and Tavel, Opin. HIV AIDS 5 (2010) 466.

5. P.R. Hagner, A. Schneider and R.B. Gartenhaus, Blood 115 (2010) 2127.

6. M. Mojic, S. Mijatovic, D. Maksimovic-Ivanic et al., Mol. Pharmacol. 82 (2012) 700.

7. G. Beichen, P.P. Roux, S. Mijatovic et al., Biochim. Biophys. Acta 1849 (2015) 753.

8. T. Kondo, Radiation Emergency Medicine 2 (2013) 1.

9. M. Laplante and D.M. Sabatini, Cell. 149 (2012) 274.

10. Kurnia, Y. Suzuki, S. Budiningsih et al., Austral. Asian J. Cancer 8 (2009) 93.

11. T. Natarajan, M. Anandi and D. Aiswarya, Biochimie 121 (2016) 13.

12. D. Lane and A. Levine, Cold Spring Harb Perspect. Biol. 2 (2010)1.

13. I. Kurnia, S. Budiningsih, S. Setiawan et al., Indonesian Journal of Nuclear Science and Technology 14 (2013) 51. (in Indonesian)

14. Kurnia, S. Budiningsih, S. Setiawan et al., Hayati Journal of Biosciences 21 (2014) 173.

15. S. Pathy, L. Kumar, R.M. Pandey et al., Asian Pacific Journal of Cancer Prevention 16 (2015) 5075.

16. D. Ploton, M. Menager, P. Jeannesson et al., Histochem. J. 18 (1986) 5.

17. Fakhrjou, A.D. Tabrizi, M. Ghojazadeh et al., Asian Pacific Journal of Cancer Prevention 14 (2013) 4815.

18. L.A.H. Hernandez, M. Moreno, A. Rey et al., Radiation Oncology 7 (2012) 1.

19. S. Shin, L. Wolgamot, Y. You et al., PNAS 108 (2011) E1205.

20. H.Y. Ren, J. Wang, F. Yang et al., Oncotarget 6 (2015) 4080.

21. L. Zhang, W. Handong, J. Xu et al., Toxicol. Lett. 228 (2014) 248. 
22. X. Li, Z. Li, W. Zhou et al., Cell Death and Disease 4 (2013) e803.

DOI:10.1038/cddis.2013.331
23. F.J. Esteva, H. Guo, S. Zhang et al., The American Journal of Pathology 177 (2010) 1647. 